\title{
The Effect of Physical Exercise on Brain-Derived Neurotrophic Factor (BDNF) in Elderly: a Systematic Review of Experimental Studies
}

\section{Yaşlılarda Fiziksel Egzersizin Beyin Kaynaklı Nörotrofik Faktör (BDNF) Üzerine Etkisi: Deneysel Çalışmaların Sistematik Derlemesi}

\author{
Yakup Zühtü Birinci ${ }^{1}$, Şenay Şahin², Şerife Vatansever², Serkan Pancar ${ }^{3}$ \\ ${ }^{1}$ Ministry of National Education Hacı Sevim Yıldız-2 Vocational and Technical Anatolian Highschool, Bursa, Turkey \\ ${ }^{2}$ Faculty of Sports Sciences, Uluda ̆̆ University, Bursa, Turkey \\ ${ }^{3}$ Ministry of National Education, Yeniceabat Anatolian Highschool, Bursa, Turkey
}

\section{Y. Z. Birinci \\ 0000-0002-1772-6014 \\ Ş. Şahin \\ 0000-0002-5670-7166 \\ Ș. Vatansever \\ 0000-0003-4722-5197 \\ S. Pancar \\ 0000-0002-4495-9796}

Geliş Tarihi/Date Received: 27.12.2018

Kabul Tarihi/Date Accepted: 26.03.2019

Yayın Tarihi/Published Online: 23.07.2019

Yazışma Adresi / Corresponding Author: Yakup Zühtü Birinci

Milli Eğitim Bakanlığı, Hacı Sevim Yıldız-2 Mesleki Ve

Teknik Anadolu Lisesi, Bursa, Turkey

E-mail:ykpbirinci@gmail.com

(C2019 Türkiye Spor Hekimleri Derneği. Tüm hakları saklıdır.

\section{ABSTRACT}

The increase in brain-derived neurotrophic factor (BDNF) along with physical exercise is thought to be one of the main reasons of the positive effect on the cognitive characteristics of elderly persons. The aim of this study is to systematically review the effects of physical exercise on BDNF in elderly people. The methodology of the electronic database survey was based on the preferred reporting clauses for systematic reviews. In this review, 21 full-text studies which have been evaluated in terms of the effects of physical exercise on BDNF in elderly people were reviewed. In most of the studies, there is serious evidence that physical exercise regulates BDNF levels in the elderly. Exercise can become a powerful prescription in combating cognitive diseases associated with neuromuscular disorders, and a sedentary lifestyle, if it can lead to the healing and regeneration of neural tissue through its effect on BDNF.

Keywords: Brain-derived neurotrophic factor, elderly, physical exercise

öz

Fiziksel egzersizle birlikte beyin kaynaklı nörotrofik faktörde (BDNF) meydana gelen artışın, yaşlıların bilişsel özellikleri üzerindeki olumlu etkinin başlıca nedenlerinden biri olduğu düşünülmektedir. Sunulan çalışmada; yaşlı bireylerde fiziksel egzersizin BDNF üzerine etkisini inceleyen çalışmaların sistematik bir şekilde gözden geçirilmesi amaçlanmaktadır. Elektronik veri tabanı araştırmasında metodoloji olarak sistematik derlemeler için tercih edilen raporlama maddeler bildirisi temel alındı. Derlemede yaşılıarda fiziksel egzersizin BDNF'ye etkilerinin değerlendirildiği deneysel nitelikli 21 tam metin çalışma incelendi. Çalışmaların büyük çoğunluğunda yaşlılarda fiziksel egzersizin BDNF düzeylerini düzenlediğini gösteren güçlü kanıtlar vardır. Egzersiz; BDNF'ye etkisi aracılığı ile nöral dokunun iyileşmesine ve yenilenmesine yol açabilirse, nöromüsküler bozukluklarla ve sedanter yaşam tarzıyla ilişkili bilişsel hastalıklarla başa çıkmada güçlü bir reçete haline gelebilir.

Anahtar Sözcükler: Beyin kaynaklı nörotrofik faktör, fiziksel egzersiz, yaşlılar

Available at: http://journalofsportsmedicine.org and

http://dx.doi.org/10.5152/tjsm.2019.142 
Cite this article as: Birinci YZ, Sahin S, Vatansever $S$ et al. The effect of physical exercise on brain derived neurotrophic factor (BDNF) in elderly: A systematic review of experimental studies. Turk $J$ Sports Med. 2019;54(4):276-87.

31 Ekim-3 Kasım 2018 tarihleri arasında Antalya'da gerçekleştirilen 16. Uluslararası Spor Bilimleri Kongresi'nde sözel bildiri olarak sunulmuştur.

\section{GÍRIŞ}

Yaşlanma ile birlikte beyin hacminde ve nöral plastisitede meydana gelen azalmalar kognitif performanslarda düşüşe neden olabilmektedir $(1,2)$. Yaşlanma süreci; yalnızca motor koordinasyon becerilerinde değil, aynı zamanda algı, hafıza, bilişsel esneklik ve problem çözme yetenekleri de dahil olmak üzere nörobilișsel fonksiyonlardaki azalmayla da ilişkilidir $(3,4)$. $\mathrm{Bu}$ bağlamda, bilișsel işlevlerdeki olumsuz yöndeki değişiklikler yaşlı insanların bağımsızlığını ve özerkliğini ciddi şekilde tehlikeye atabilmektedir (5). Son yıllarda, özellikle yaşlı bireylerde bilişsel performansı korumak ve iyileştirmek için mümkün olan tekniklerden fiziksel egzersiz reçetelerinin uygulanması yoğun şekilde bilimsel ilgi görmektedir (6).

Fiziksel açıdan aktif bir yaşam tarzı, fiziksel ve zihinsel sağlığa önemli katkılarda bulunmaktadır. Son yıllarda yapılan birçok çalışma, kardiyovasküler ve metabolik hastalıklara yakalanma riskinin fiziksel egzersizle azaldığını göstermektedir (7). Fiziksel egzersiz, anjiyogenezi, beyin sinaptogenezini ve nörogenezi etkileyebilen moleküler ve hücresel süreç dizisini uyarabilir $(8,9)$. Bununla birlikte, egzersiz ve beyin fonksiyonu arasındaki fonksiyonel ilişki, sadece hayvanlarda değil, aynı zamanda insanlarda da sağlam kanıtlar ile ortaya konulmuştur (10-13). Fiziksel egzersizin bilişsel işlevler üzerindeki yararlı etkilerinden sorumlu olan çeşitli kortikal ve subkortikal bölgelerde beyin kan akımı artışı, nörotransmiterlerin sentezi ve kullanımı gibi nörobiyolojik mekanizmalarda, BDNF sentezinde görülen artışların etkili olduğu düşünülmektedir $(14,15)$.

Fiziksel egzersiz, sağlıklı bireylerde mekânsal öğrenmeyi geliştirirken $(2,16)$ yaşlanmanın beraberinde getirdiği bilişsel gerilemeye $(17,18)$, Alzheimer'a $(19)$ ve bunamaya $(20,21)$ karşı da koruyucu etkisi bulunabilir. Daha yüksek fiziksel uygunluk düzeyindeki bireyler, bilişsel yeteneklerini, karşılaştıkları ortamın gereklerini karşılayabilmek için daha esnek bir şekilde kullanabilirler $(22,23)$. Orta yaşlarda bilişsel işlemlerde düşüşler başlamış olsa da düzenli fiziksel egzersizin bu durumu tersine çevirebildiği belirtilmektedir (24-26).

Fiziksel egzersizle birlikte BDNF'de meydana gelen artışın, yaşlıların bilişsel özellikleri üzerindeki olumlu etkinin başlıca nedenlerinden biri olduğu düşünülmektedir. BDNF temel bir proteindir, nörotropin ailesinin bir üyesidir ve merkezi sinir sistemi (MSS) üzerinde yapısal ve fonksiyonel plastisiteye pozitif olarak müdahale ettiğinden nörobiyolojide çok önemli bir role sahiptir $(27,28)$. Özellikle BDNF proteini, kısa vadede bilișsel performans ve uzun vadede beyin morfolojisindeki (örneğin, plastisitedeki) uyarlamalar için hayati önemdedir $(27,29)$.

BDNF konsantrasyonlarının yaş artışı ile değiştiği de bilinmektedir (30). Foster ve ark.na (31) göre, BDNF'nin periferde azalması yaşa bağlı nöronal kayıp ile ilişkilidir. Erickson ve ark.nın (32) yaptıkları çalışmada yaşlıların daha düşük BDNF derișimine sahip oldukları, daha küçük hipokampal hacimleri olduğu ve uzamsal bellek görevleri üzerinde daha kötü performans gösterdikleri ortaya konulmuştur. Araştırmalar BDNF'nin beynin biçim ve işlevinde araçsal bir rol oynadığını göstermiștir (33-35). İnsanlar üzerine yapılan çalışmalar, BDNF derişimlerinin yalnızca yaşlı yetişkinlerde bellek için önemli olan mekânsal bellek performansı ve beyin bölgelerinin hacmi ile ilgili olmadığını, aynı zamanda Alzheimer hastalığı için potansiyel bir biyolojik belirteç olduğunu da göstermiş̧tir $(33,36,37)$. Benzer şekilde BDNF'nin nöronların büyümesini ve korunmasını düzenleyerek Huntington, Alzheimer, bunama ve Parkinson gibi nörodejeneratif hastalıkların yol açtığı yetersiz bilişsel işlevler üzerinde çok önemli etkileri olduğu düşünülmektedir $(26,32)$. 
Yaşlı insanlarda yapılan deneysel çalışmalar, egzersiz uygulamalarının birçok olumsuz durumdaki bilişsel durumu değiştirebileceğini ya da daha kötüye gitmesinin önüne geçebileceğini göstermektedir (38-40). Bu etkilerin olası kaynaklarını anlamanın, farmakolojik yan etkilerin ve tedavi bașarısızlıklarının önlenmesi ve bilișsel gelişimin arttırılması için egzersiz uygulamalarının uyarlanmış klinik reçeteleri için önemli olacağ düşünülmektedir (12). Buradan hareketle sunulan çalıșmada; yaşlı bireylerde fiziksel egzersizin BDNF üzerine etkisini inceleyen çalışmaların sistematik bir şekilde gözden geçirilmesi amaçlanmaktadır.

\section{YÖNTEM}

Sistematik derleme York Üniversitesi Ulusal Sağlık Araştırmaları Enstitüsü tarafından geliştirilen Centre for Reviews and Dissemination (CRD) 2009 rehberi doğrultusunda yapıldı. Elektronik veri tabanı sistematik araştırmasında metodoloji olarak sistematik derlemeler için tercih edilen raporlama maddeler bildirisi [Preferred Reporting Items for Systematic Reviews and Meta-Analyses (PRISMA) statement] temel alındı (41) ve çalıșma PRISMA ile gözden geçirildi (Şekil 1.).

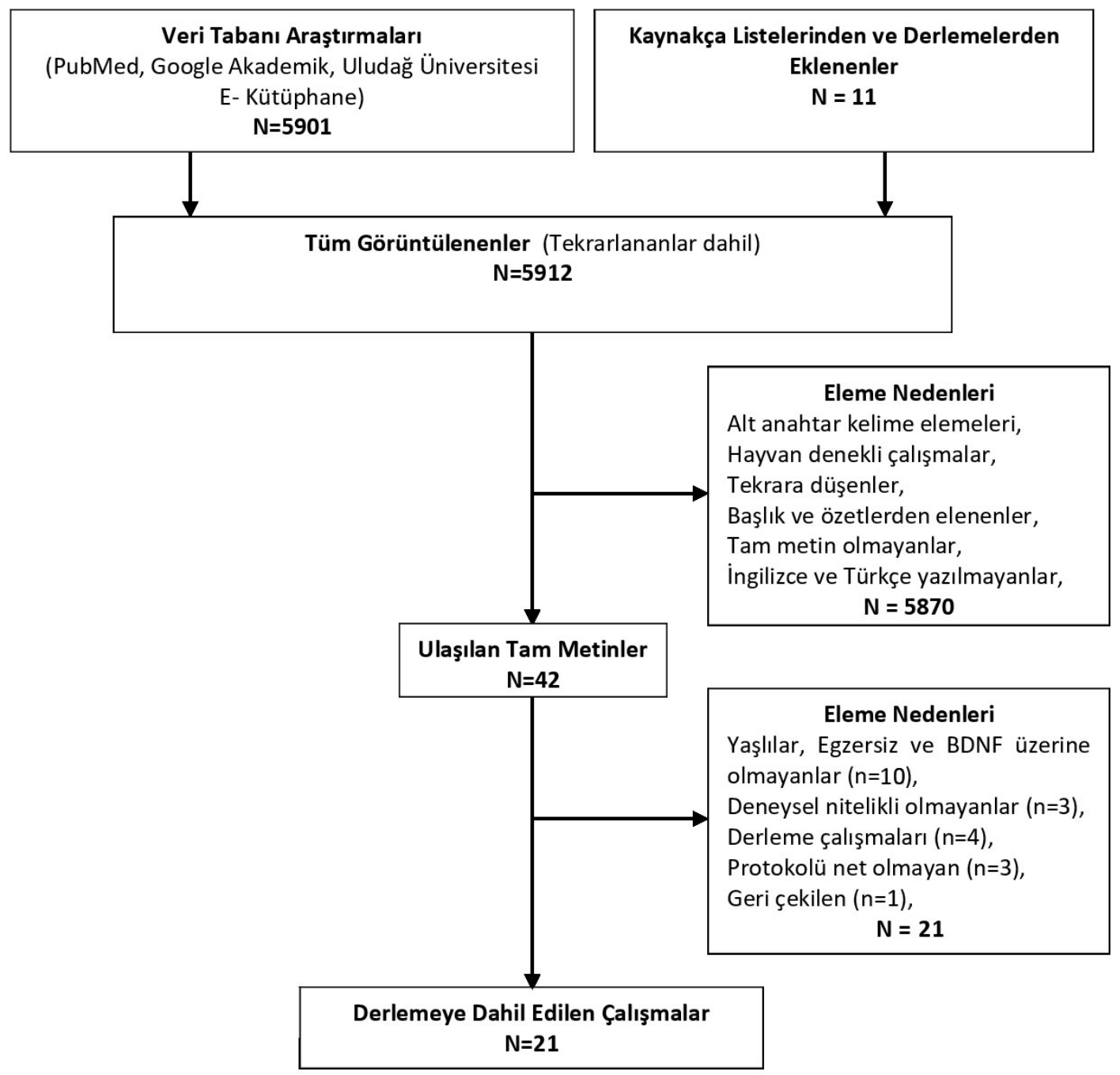

Şekil 1. Akış Şeması (PRISMA, Liberati ve ark., 2009) 
Yapılacak sistematik derleme için literatür taraması; Uludă̆ Üniversitesi e-Kütüphanesi, PubMed ve Google Akademik veri tabanlarında, Ağustos 2018-Eylül 2018 tarihleri arasında, "BDNF and exercise", "BDNF ve egzersiz", "brain derived neurotrophic factor" "beyin kaynaklı nörotrofik faktör" anahtar sözcükleri ile İngilizce ve Türkçe olarak tarandı. Daha sonra aramayı daraltmak adına "older adults", "elderly", "physical exercise", "yaşlılar", "fiziksel egzersiz" gibi alt anahtar sözcükler kullanıldı. Sunulan çalışmada yaşlıların $(\geq 65)$ katılımcı olduğu, BDNF'ye akut ya da kronik egzersizin etkilerinin değerlendirildiği, İngilizce veya Türkçe dilinde yazılmış, tam metin ve deneysel nitelikteki çalışmalar incelendi. Fiziksel egzersizin yaşlılarda BDNF üzerine etkisinin olup olmadığı sorusuna yanıt verebilecek çalışmalara ulaştırabilir nitelikte katılım ve dışlama kriterleri seçildi.

\section{Klinik ve Araştırma Sonuçları}

Derleme kapsamına; dışlama ve dâhil edilme kriterleri göz önünde bulundurulduğunda 21 çalışma alınıp incelendi. Derleme kapsamında incelenen çalışmaların 14'ünde BDNF düzeylerinde fiziksel egzersize bağlı bir artış olduğu saptandı. Ancak, diğer yedi çalışmadan ikisi, fiziksel egzersiz sonrası BDNF düzeylerinde istatistiksel anlamda önemli olmasa da küçük artışlar olduğunu, beşi ise egzersiz uygulamaları sonucunda BDNF düzeyinde artış/değişiklik olmadığını saptamıştı (Tablo.1).

Derleme kapsamındaki çalışmaların katılımcı özellikleri incelendiğinde; 11 çalışmada sağlıklı yaşlılar, yedi çalışmada hasta yaşlılar [Hafif bilişsel bozukluk, glükoz intoleranslı, depresif, Parkinson, tip-2 diabet, kırılganlık (ömür boyu birçok fizyolojik sistemde yaşanan kümülatif düşüş sonucu tanımlanan geriatrik sendrom), hareketi sınırlanmış] üzerinde BDNF-egzersiz ilişkisi incelenmişken, diğer üç çalışmada sağlıklı ve hasta yaşlıların egzersizin BDNF düzeylerine etkisi açısından karşılaştırıldığı belirlendi.

Erickson ve ark., 120 sağlıklı yaşlı katılımcıya bir yıl boyunca haftada üç gün $40 \mathrm{dk}$ 'llk orta şiddetli aerobik yürüyüş [ilk yedi hafta $\mathrm{KAH}_{\max }$ (maksimum kalp atım hızı)'ın \%50-60'ında, 7. haftadan sonra $\mathrm{KAH}_{\text {max }}$ 'In \%60-75'inde] uygulamasında bulunmuştur. BDNF düzeyleri karşılaştırıldığında; aerobik egzersiz grubundaki katılımcılarda yüksek BDNF artışı saptanmıştır. $\mathrm{Bu}$ artışın aynı zamanda katılımcıların hipokampal hacimleri arasında oluşan fark ile de ilişkili olduğu belirtilmiştir (32).

Voss ve ark. (42) 65 sağlıklı yaşlı katılımcı ile yaptıkları çalışmada; egzersiz grubuna bir yıl süreyle haftada üç gün ortalama $40 \mathrm{dk}$ 'dan olușan yürüyüș egzersizleri, kontrol grubuna ise esneklik, denge ve tonik egzersizleri yaptırmışlardır. Tüm katılımcıların uygulamalar sonucunda BDNF düzeylerinde artıș saptanmıș olsa da, gruplar arasında istatistiksel olarak anlamlı fark bulunmamıștır. Fakat bilateral parahipokampus ile bilateral orta temporal girus arasında artan temporal lob bağlantısının artmış BDNF, IGF-1 (insulin-like growth factor type 1) ve VEGF (vascular endothelial growth factor) ile ilişkili olduğu ortaya konulmuştur (42). Benzer şekilde Leckie ve ark. 92 sağlıklı yaşlıda bir yıl süreyle yürüyüş egzersizlerinin bilişsel esneklik, seçici dikkat, görev değiștirme ve engelleme gibi beynin yürütücü işlev becerileri üzerine etkilerini araştırmışlardır. İlk yedi hafta (hf) süreyle $\mathrm{KAH}_{\max }$ 'In \%50-60'ında yapılan aerobik egzersizlerin şiddeti, 7. haftadan sonra $\mathrm{KAH}_{\max }$ 'in \%60-75'ine çıkarılmıştır. Sonuç olarak aerobik egzersiz grubundaki 65 yaş üstü katılımcıların BDNF düzeylerinde istatistiksel olarak anlamlı bir artış saptanmıştır (43). 
Tablo1. Fiziksel egzersizin BDNF üzerine etkilerini inceleyen çalışmaların ayrıntıları ve bulguları

\begin{tabular}{|c|c|c|c|c|c|c|c|}
\hline Yayın & Katılımcı Niteliği & $\mathrm{N}$ & Süre & Egzersiz Türü & Egzersiz Şiddeti & $\begin{array}{l}\text { Gruplar } \\
\text { Ortalama Yaș (yıl) }\end{array}$ & $\begin{array}{l}\text { BDNF } \\
\text { Yanitı }\end{array}$ \\
\hline $\begin{array}{l}\text { Erickson ve } \\
\text { ark., } 2011\end{array}$ & Sağlıklı & 120 & $52 \mathrm{hf}$ & $\begin{array}{l}\text { Aerobik yürüyüş } 3 \mathrm{~g} / \mathrm{hf} \\
1-7 \mathrm{hf:} 10-40 \mathrm{dk} \\
7-52 \mathrm{hf:} 40 \mathrm{dk}\end{array}$ & $\begin{array}{l}\text { Aerobik yürüyüș: } 1-7 \text { hf: } \mathrm{KAH}_{\max } \% 50-60 ; 7- \\
52 \quad \text { hf: } \% 60-75 ; \quad \text { Stretching: } \\
\text { esneklik/tonik/denge } \\
\text { 13-15 RPE }\end{array}$ & $\begin{array}{l}\text { Egzersiz/Stretching } \\
67.6 \pm 5.8 / 65.5 \pm 5.4\end{array}$ & $\Uparrow / \Uparrow$ \\
\hline $\begin{array}{l}\text { Baker ve } \\
\text { ark., } 2010\end{array}$ & HBB & 29 & $24 \mathrm{hf}$ & $\begin{array}{lr}\text { Koşu } & \text { bandl, } \\
\text { eliptik/sabit } & \text { bisiklet; } \\
4 \mathrm{~g} / \mathrm{hf}, 45-60 \mathrm{dk} & \end{array}$ & (\%75-85 KAH rezerv $) /(\% 50 \mathrm{KAH}$ rezerv $)$ & $\begin{array}{l}\text { HIT/Stretching } \\
\text { E } 70.9 \pm 6.7 \text { K } 65.3 \pm 9.4 / \\
\text { E } 70.6 \pm 6.1 \text { K } 74.6 \pm 11.1\end{array}$ & $\Rightarrow / \Rightarrow$ \\
\hline $\begin{array}{l}\text { Baker ve } \\
\text { ark., } 2010\end{array}$ & Glükoz intoleransı & 28 & 6 ay & $\begin{array}{l}\text { Koşu bandl, eliptik, } \\
\text { sabit bisiklet; } 4 \mathrm{~g} / \mathrm{hf}, \\
45-60 \mathrm{dk}\end{array}$ & $(\% 75-85 \mathrm{KAH}$ rezerv $) /(\% 50 \mathrm{KAH}$ rezerv $)$ & $\begin{array}{l}\text { HIT/Stretching } \\
71.6 \pm 7.5 / 66.0 \pm 6.0\end{array}$ & $\Rightarrow / \Rightarrow$ \\
\hline $\begin{array}{l}\text { Voss ve } \\
\text { ark., } 2013\end{array}$ & Sağlıklı & 65 & $1 \mathrm{yll}$ & $\begin{array}{l}\text { Aerobik yürüyüş/ } \\
\text { Esneklik/tonik/denge } \\
3 \mathrm{~g} / \mathrm{hf} / 40 \mathrm{dk}\end{array}$ & $\begin{array}{l}\text { Aerobik yürüyüș: 1-7 hf: } \mathrm{KAH}_{\text {rezerv }} \% 50-60 ; 7 \\
\text { hf-son: \%60-75; Esneklik/tonik/denge; 13- } \\
15 \mathrm{RPE}\end{array}$ & $\begin{array}{l}\text { Aerobik/Kontrol (denge } \\
\text { esneklik, tonik egzersiz) } \\
67.3 \pm 5.8 / 65.4 \pm 5.2\end{array}$ & $\Uparrow / \Uparrow$ \\
\hline $\begin{array}{l}\text { Pereira ve } \\
\text { ark., } 2013\end{array}$ & Depresif kadınlar & 167 & $10 \mathrm{hf}$ & $\begin{array}{l}\text { Aerobik yürüyüss, } \\
\text { Kuvvet: } 3 \mathrm{~g} / \mathrm{hf}, 40 \mathrm{dk}\end{array}$ & $\begin{array}{l}\text { Aerobik: } \mathrm{KAH}_{\max } \% 65-80 \\
\text { Kuvvet: } 1-2 \text { hf: } \% 50(1 \mathrm{RM}) ; 2-10 \text { hf: } \% 75\end{array}$ & $\begin{array}{l}\text { Aerobik/Kuvvet } \\
70.3 \pm 4.5 / 71.0 \pm 4.8\end{array}$ & $\Rightarrow / \Uparrow$ \\
\hline $\begin{array}{l}\text { Leckie ve } \\
\text { ark., } 2014\end{array}$ & Sağlıklı & 92 & $1 \mathrm{yll}$ & $\begin{array}{l}\text { Aerobik yürüyüs, } \\
\text { stretching: } 40 \mathrm{dk}\end{array}$ & $\begin{array}{l}\text { Aerobik: } 1-7 \text { hf: } \mathrm{KAH}_{\max } \% 50-60 ; 7 \text { hf- son: } \\
\% 60-75\end{array}$ & $\begin{array}{l}\text { Aerobik/stretching } \\
67.2 \pm 5.4 / 66.4 \pm 5.8\end{array}$ & $\Uparrow / \Rightarrow$ \\
\hline $\begin{array}{l}\text { Maass ve } \\
\text { ark., } 2016\end{array}$ & Sağlıklı & 40 & $4 \mathrm{hf}$ & $\begin{array}{l}\text { Aralıklı yürüyüş ve } \\
\text { koşu: } 3 \mathrm{~g} / \mathrm{hf} / 30 \mathrm{dk} \\
\text { kontrol: } 2 \mathrm{~g} / \mathrm{hf} / 45 \mathrm{dk}\end{array}$ & $\begin{array}{l}\text { Yürüyüş ve koşu: ilk } 4 \text { hf: } \text { KAH }_{\text {rezerv } \% 65 ;} \% \text { Kontrol: } \\
\text { sonrasında } \quad \% 70 ; \\
\text { rahatlama/stretching }\end{array}$ & $\begin{array}{l}\text { Egzersiz/Kontrol } \\
68.4 \pm 4.3\end{array}$ & $\Rightarrow / \Rightarrow$ \\
\hline $\begin{array}{l}\text { Marusiak } \\
\text { ve ark., } \\
2015\end{array}$ & Parkinson/Sağlıklı & 22 & $\begin{array}{l}8 \mathrm{hf} / 24 \\
\text { seans }\end{array}$ & $\begin{array}{l}\text { Aralıklı ergonometre } \\
3 \mathrm{~g} / \mathrm{hf} / 40 \mathrm{dk}\end{array}$ & $\begin{array}{l}\text { Yavaş bölüm KAH } \mathrm{KAx}_{\max } \% 62,2 \mathrm{dk}, \leq 60 \mathrm{rpm} \\
\text { Hızlı bölüm KAH } \% 68,3 \mathrm{dk}, \geq 60 \mathrm{rpm}\end{array}$ & $\begin{array}{l}\text { Parkinson/Sağlıklı } \\
71 \pm 10 / 77 \pm 8\end{array}$ & $\Uparrow / \Rightarrow$ \\
\hline $\begin{array}{l}\text { Allard ve } \\
\text { ark., } 2017\end{array}$ & HBB (13)/ Sağlıklı & 24 & 6 ay & $\begin{array}{l}\text { Yürüyüş } \quad 3 \mathrm{~g} / \mathrm{hf} / 45- \\
60 \mathrm{dk} ; \\
\text { Stretching } 40 \mathrm{dk}\end{array}$ & Aerobik yürüyüş: $\mathrm{VO}_{2 \max } \% 50-70$ & $\begin{array}{l}\text { Aerobik/Stretching } \\
73.1 \pm 7.6 / 70.4 \pm 6.3\end{array}$ & $\Uparrow / \Uparrow$ \\
\hline $\begin{array}{l}\text { Zoladz ve } \\
\text { ark., } 2015\end{array}$ & Parkinson & 12 & $\begin{array}{l}8 \mathrm{hf} / 24 \\
\text { seans }\end{array}$ & $\begin{array}{l}\text { Aralıklı bisiklet } \\
\text { ergonometresi } \\
3 \mathrm{~g} / \mathrm{hf} / 40 \mathrm{dk}\end{array}$ & $\begin{array}{l}\text { Bisiklet: 1-2 hf: } \mathrm{KAH}_{\max } \% 60 ; 3-4 \mathrm{hf:} \% 65 ; 5- \\
6 \text { hf:\%70; 6-8 hf: \%75; Yavaş bölüm: 2dk, } \\
\leq 60 \mathrm{rpm} \text {; Hılı bölüm: 3dk, } \approx 80-90 \mathrm{rpm}\end{array}$ & $\begin{array}{l}\text { Parkinson } \\
70 \pm 3\end{array}$ & $\Uparrow$ \\
\hline $\begin{array}{l}\text { Schega ve } \\
\text { ark., } 2016\end{array}$ & Sağlıklı & 36 & $4 \mathrm{hf}$ & $\begin{array}{l}\text { Normobarik } \\
\text { hipoksik bisiklet } \\
\text { 3g/hf/30dk }\end{array}$ & $\begin{array}{l}\text { Bisiklet: } 1-2 \text { hf: } \mathrm{KAH}_{\max } \% 65-70 ; 2-4 \mathrm{hf} \\
\% 70-75 \\
\text { Kontrol: placebo hava karıșımı }\end{array}$ & $\begin{array}{l}\text { Normobarik hipoksi/ } \\
\text { Kontrol } \\
66.4 \pm 3.3 / 67.9 \pm 4.4\end{array}$ & $\Uparrow / \Uparrow$ \\
\hline $\begin{array}{l}\text { Anderson } \\
\text { ve ark., } \\
2012\end{array}$ & Sağlıklı & 63 & 3 ay & $\begin{array}{l}\text { Siber (3D) bisiklet } \\
5 \mathrm{~g} / \mathrm{hf} / 45 \mathrm{dk}\end{array}$ & Bisiklet: $\mathrm{KAH}_{\text {rezerv }} 60 \%$ & $\begin{array}{l}\text { Siber bisiklet/Kontrol } \\
75.7 \pm 9.9 / 81.6 \pm 6.2\end{array}$ & $\Uparrow / \Uparrow$ \\
\hline $\begin{array}{l}\text { Brinkmann } \\
\text { ve ark., }\end{array}$ & Tip-2 Diabet & 8 & Akut & $\begin{array}{l}\text { Exergame, sabit } \\
\text { bisiklet: } 30 \mathrm{dk}\end{array}$ & Exergame bisiklet: RPE 14-15 & $\begin{array}{l}\text { Bisiklet/Exergame } \\
71 \pm 4\end{array}$ & $\Rightarrow / \Uparrow$ \\
\hline
\end{tabular}




\begin{tabular}{|c|c|c|c|c|c|c|c|}
\hline 2017 & & & & & & & \\
\hline $\begin{array}{l}\text { Coelho ve } \\
\text { ark., } 2011\end{array}$ & Kirılgan & 48 & $10 \mathrm{hf}$ & $\begin{array}{l}\text { Dinamik direnç } \\
\text { egzersizi: } 3 \mathrm{~g} / \mathrm{hf} / 60 \mathrm{dk}\end{array}$ & $\begin{array}{l}1-2 \text { hf: } 1(\mathrm{RM}) \% 50 ; 2-10 \mathrm{hf} \% 75 \\
8 \text { set } 8 \text { tekrar }\end{array}$ & $\begin{array}{l}\text { Kırılgan olmayan/ } \\
\text { Kırılganlık öncesi } \\
70.5 \pm 4.6 / 72.5 \pm 4.3\end{array}$ & $\Uparrow / \Uparrow$ \\
\hline $\begin{array}{l}\text { Hvid ve } \\
\text { ark., } 2017\end{array}$ & $\begin{array}{l}\text { Hareketi } \\
\text { sinırlanmıș }\end{array}$ & 47 & $12 \mathrm{hf}$ & $\begin{array}{l}\text { HIT, güç egzersizleri } \\
2 \mathrm{~g} / \mathrm{hf}\end{array}$ & $\begin{array}{l}\text { 1-7 hf: : } 1 \text { (RM) \%70 3set/10 tekrar } \\
7-12 \text { hf: } 1 \text { (RM) } \% 803 \text { set } / 8 \text { tekrar }\end{array}$ & Egzersiz/Kontrol & $\Rightarrow / \Rightarrow$ \\
\hline $\begin{array}{l}\text { Forti ve } \\
\text { ark., } 2015\end{array}$ & Sağlıklı & 56 & $\begin{array}{l}12 \mathrm{hf} / 36 \\
\text { seans }\end{array}$ & $\begin{array}{l}\text { Direnç egzersizi } \\
3 \mathrm{~g} / \mathrm{hf}\end{array}$ & $\begin{array}{l}\text { Yüksek: } 1(\mathrm{RM}) \% 80 ; 2 \text { set/1 dk ara/10-15 } \\
\text { tk; } \\
\text { Düşük: } 1(\mathrm{RM}) \% 20 ; 1 \text { set/80-100 tekrar; } \\
\text { Düşük+: } 1(\mathrm{RM}) \% 20,60 \text { tekrar + } \% 40,10-20 \\
\text { tk }\end{array}$ & $\begin{array}{l}\text { Yüksek/Düşük /Düşük+ } \\
68 \pm 5\end{array}$ & $\begin{array}{l}\Rightarrow / \Rightarrow \\
\text { Düşük+ } \\
\text { erkek } \Uparrow\end{array}$ \\
\hline $\begin{array}{l}\text { Matura ve } \\
\text { ark., } 2017\end{array}$ & Sağlıklı & 53 & $12 \mathrm{hf}$ & $\begin{array}{l}\text { Bisiklet ergometresi; } \\
\text { Aerobik egzersiz } \\
3 \mathrm{~g} / \mathrm{hf} / 30 \mathrm{dk}\end{array}$ & $\begin{array}{l}\text { Aerobik: \%64 } \mathrm{VO}_{2} \text { max'a eşit } \mathrm{W} \text { cinsinden iş } \\
\text { yükü }\end{array}$ & $\begin{array}{l}\text { Aerobik/Kontrol } \\
73.3 \pm 5.5 / 77 \pm 8.1\end{array}$ & $\Rightarrow / \Rightarrow$ \\
\hline $\begin{array}{l}\text { Rehfeld ve } \\
\text { ark., } 2018\end{array}$ & Sağlıklı & 38 & 6 ay & $\begin{array}{l}\text { Dans/direnç } \\
\text { egzersizleri } \\
\text { (dayanıklılık+kuvvet+ } \\
\text { esneklik) } 2 \mathrm{~g} / \mathrm{hf} \\
90 \mathrm{dk} / 3 \times 20 \mathrm{dk}\end{array}$ & Belirtilmemiş, KAH gözlemlenmiş & $\begin{array}{l}\text { Spor/Dans } \\
(63-80)\end{array}$ & $\Rightarrow / \Uparrow$ \\
\hline $\begin{array}{l}\text { Vaughan ve } \\
\text { ark., } 2014\end{array}$ & Sağlıklı & 49 & $16 \mathrm{hf}$ & $\begin{array}{lr}\text { Çoklu egzersiz modeli: } \\
\text { Aerobik } & \text { (kardio), } \\
\text { direnç } & \text { (kuvvet), } \\
\text { çeviklik } & \text { esneklik, } \\
\text { denge, } & \text { koordinasyon } \\
\text { (motor); } & \text { 2g/hf/60dk }\end{array}$ & 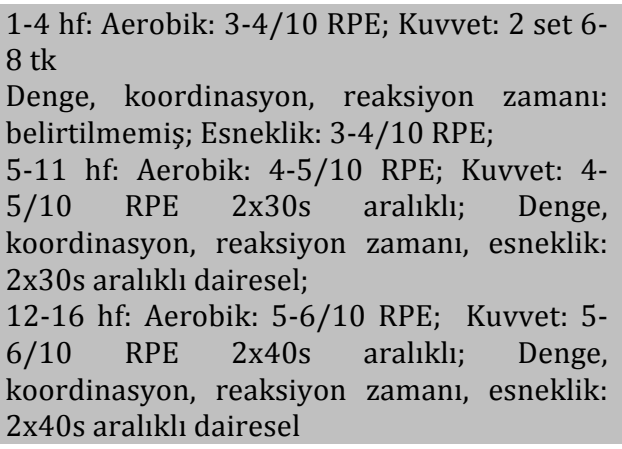 & $\begin{array}{l}\text { Uygulama/Kontrol } \\
69.0 \pm 3.1 / 68.8 \pm 3.5\end{array}$ & $\Uparrow / \Rightarrow$ \\
\hline $\begin{array}{l}\text { Walsh ve } \\
\text { ark., } 2015\end{array}$ & Sağlıklı & 10 & $8 \mathrm{hf}$ & $\begin{array}{ll}\text { Alt ekstremite } & \text { direnç } \\
\text { egzersizi } & \text { (squat, } \\
\text { çift\&tek bacak } & \text { press); } \\
3 \mathrm{~g} / \mathrm{hf} & \end{array}$ & $\begin{array}{l}4 x 8-10 \text { tekrar } 90 \text { s dinlenme } \\
1 \text { hf: } 1 \text { (RM) } \% 60 ; 2-4 \text { hf: } \% 70 ; 4-8 \text { hf: } \% 80\end{array}$ & Tüm katılımcılar & $\begin{array}{l}\text { Akut } \Uparrow \\
8 \mathrm{~h} \Rightarrow\end{array}$ \\
\hline $\begin{array}{l}\text { Nascimento } \\
\text { ve ark., } \\
2014\end{array}$ & $\begin{array}{l}\text { HBB (37)/ } \\
\text { Sağglıklı }\end{array}$ & 67 & $16 \mathrm{hf}$ & $\begin{array}{l}\text { Çoklu egzersiz (kassal } \\
\text { dayanıklılı, aerobik, } \\
\text { denge, koordinasyon,); } \\
3 \mathrm{~g} / \mathrm{hf} / 60 \mathrm{dk}\end{array}$ & $\mathrm{KAH}_{\max } \% 60-80$ & $\begin{array}{l}\text { Egzersiz Sağlıklı/HBB } \\
\text { Kontrol Sağlıklı/HBB } \\
66.6 \pm 7.9 / 67.3 \pm 5.3 \\
68.1 \pm 5.7 / 68.5 \pm 5.9\end{array}$ & $\begin{array}{l}\Uparrow / \Uparrow / \\
\Rightarrow / \Rightarrow\end{array}$ \\
\hline
\end{tabular}

MS: mültipl skleroz; HBB: hafif bilişsel bozukluk; HIT: yüksek şiddetli egzersiz; MD: majör depresyon; KAH rezerv; kalp atım hızı rezervi; RPE : algılanan efor zorluk derecesi; 1 RM: 1 tekrar maksimumu; E: erkek; K: kadın; $\Uparrow:$ artış; $\Rightarrow$ : değişiklik yok. 
Schega ve ark.; dört hafta boyunca haftada üç gün $30 \mathrm{dk}$ bisiklet ergometresi ile uyguladıkları aerobik egzersizle (1-2 hf: $\mathrm{KAH}_{\max } \% 65-70,2-4$ hf: $\mathrm{KAH}_{\max }$ \%70-75) kombine ettikleri normobarik hipoksi egzersizinin sağlıklı yaşlılarda BDNF düzeyi üzerine etkilerini incelemişlerdir. Egzersizler sonucunda fiziksel ve bilişsel performans ve BDNF düzeyi artmıştır fakat gruplar arasında BDNF düzeyi artışı açısından istatistiksel olarak anlamlı bir fark çıkmamıştır (44). Anderson-Hanley ve ark. yaşlılarda üç ay süreyle sanal gerçeklik özellikli bisiklet ile düzenledikleri egzersizlerin [ $\mathrm{KAH}_{\text {rezerv }}$ (alp atım hızı rezervi) \%60] BDNF düzeylerine etkisini incelemişlerdir. Araştırma sonucunda sanal gerçeklik özellikli bisiklet grubundaki katılımcıların BDNF düzeylerinde artışın daha fazla olduğu saptanmıştır (45).

Yürüyüş ve bisiklet egzersizlerinden farklı olarak Rehfeld ve ark. (46) yaptıkları çalışmada; 38 kişilik sağlıklı yaşlı katılımcıdan oluşturdukları dans grubuna altı ay boyunca haftada iki gün $90 \mathrm{dk}$ her iki haftada bir kol-ayak koordinasyonu ve uzaysal oryantasyon temelli yeni dans çeşidi öğreterek, spor grubuna ise yine aynı sürelerde kuvvet, dayanıklılık ve esneklik egzersizleri yaptırmışlardır. Egzersizler sonucunda dans grubundaki katılımciların BDNF düzeylerinde istatistiksel olarak anlaml artış saptanmıştır (46). Vaughan ve ark. 49 kişilik sağlıklı yaşlı kadın katılımcı üzerinde yaptıkları çalışmada; 16 hafta süreyle haftada iki gün $60 \mathrm{dk}$ 'dan oluşan ve her bir seansta aerobik, kuvvet, denge, koordinasyon ve reaksiyon zamanı egzersizleri içeren çoklu egzersiz modeli uygulamışlardır. Egzersiz grubu katılımcılarının BDNF düzeylerinde artış saptanmıştır (47).

Sağlıklı yaşlılarda yapılan bu çalışmaların sonuçlarından farklı olarak; Walsh ve ark., 10 kişilik sağlıklı yaşlı katılımcıya sekiz hafta boyunca haftada üç gün alt ekstremite direnç egzersizleri [4x8-10 tekrar, 1 hf: 1 maksimum tekrar (MT, RM) \%60, 2-4 hf: 1(MT) \%70, 4-8 hf: 1(MT) \%80] uygulamışlardır. Uygulama sonucunda katılımcıların BDNF düzeylerinde her akut egzersiz sonrasında BDNF artışı gözlenirken, sekiz haftalık tüm uygulama sonucunda artış saptanmamıștır (48).

Forti ve ark. 56 yaşlı katılımcıya 12 hafta boyunca haftada üç gün direnç egzersizleri yaptırmışlardır. Direnç egzersizlerini; yüksek [1(MT) \%80, 2 set; $1 \mathrm{dk}$ dinlenme; 10-15 tekrar], düşük [1(MT) \%20, 1 set 80-100 tekrar] ve düşük-orta [1(MT) \%20 60 tekrar + 1(MT) \%40 ile $\quad 10-20$ tekrar] şiddetlerinde gerçekleştirmişlerdir. Sonuçlar incelendiğinde; sadece erkek katılımcıların düşük-orta şiddetli kombine egzersizlerde BDNF düzeylerinde artış olduğu gözlemlenmiştir. Araştırmacılar bu sonucun oluşmasının nedeninin belirsiz olduğunu ve literatürde farklı sonuçların çokça bulunduğunu belirterek gelecekteki çalışmalarda cinsiyet değişkeninin BDNF'ye etkisinin incelenmesi gerektiğini bildirmişlerdir. Ayrıca hayvan çalışmalarında gösterilmiş östrojen düzeyinin BDNF'ye olumlu etkisi ve bu çalışmadaki katılımcıların yaşları sebebiyle menopoz durumu özelliklerinin bu etkiyi baskılamış olabileceği görüşü de belirtilmiştir (49).

Direnç egzersizlerinden farklı olarak Maass ve ark. (50) yaptıkları çalıșmada; egzersizle birlikte indüklenip beynin yapısını değiștirebildiği düşünülen BDNF gibi biobelirteçlerin yaşlılarda üç aylık bir egzersiz girişiminden sonraki düzeylerini incelemeyi amaçlamışlardır. Fiziksel egzersiz grubundaki katılımcılara ilk dört hafta $\mathrm{KAH}_{\text {rezerv'nin }} \% 65$ 'inde, kalan haftalarda $\mathrm{KAH}_{\text {rezerv' }}$ nin $\% 70$ 'inde olmak üzere haftada üç gün $30 \mathrm{dk}$ yürüyüş; germe egzersizi grubundaki katılımcllara ise haftada iki gün $45 \mathrm{dk}$ stretching ve kas rahatlatma egzersizleri yaptırılmıştır. Sonuçlar incelendiğinde; gruplardaki BDNF değişikliğinin istatistiksel olarak anlamlı olmadığı saptanmıştır (50). Matura ve ark.nın yaptıkları çalışmada; 12 hafta boyunca haftada üç gün $30 \mathrm{dk}{ }^{\prime} l \mathrm{k}$ bireyselleştirilmiş bisiklet ergometresi yardımıyla aerobik egzersiz programı (\%64 $\mathrm{VO}_{2}$ max'a eşdeğer $\mathrm{W}$ cinsinden iş yükü) 53 sağlıklı yaşlı katılımcıya uygulatılmıştır. Çalışma sonucunda girişim grubundaki katılımcıların BDNF düzeylerinde değişiklik saptanmamıştır (51). 
Hasta yaşlı katılımcıların yer aldığı çalışmalar incelendiğinde; Brinkmann ve ark. araştırmalarında tip-2 diabetli yaşllara uygulanan sabit bisiklet ve exergame (fiziksel hareket temelli video oyunları) özellikli bisiklette eşit şiddetteki submaksimal $30 \mathrm{dk} \mathrm{k}^{\prime} \mathrm{lk}$ akut egzersizin [RPE (algllanan efor zorluk derecesi)=14-15] BDNF düzeyleri üzerine etkilerini karşılaştırmışlardır. Sonuçlar incelendiğinde bilişsel uyarı sağlayabilen exergame destekli fiziksel egzersizin daha çok BDNF artışı sağladığı saptanmıştır (52). Zoladz ve ark. fiziksel egzersizin yaşlı Parkinson hastalarında BDNF düzeyleri üzerindeki etkilerini incelemişlerdir. Katılımcılara sekiz hafta boyunca haftada üç gün $60 \mathrm{dk}$ 'lık orta şiddette [1-2 hf: $\mathrm{KAH}_{\max } \% 60,3-4 \mathrm{hf}: \mathrm{KAH}_{\max }$ \%65, 5-6 hf: $\mathrm{KAH}_{\max } \% 70$, 6-8 hf: $\left.\mathrm{KAH}_{\max } \% 75\right]$ aralıklı (yavaş bölüm $2 \mathrm{dk}, \leq 60 \mathrm{rpm}$; hızlı bölüm $3 \mathrm{dk}, \approx 80-90 \mathrm{rpm}$ ) egzersiz yaptırılmıștır. Egzersizler sonrası Parkinson hastası yaşlılardaki bazal BDNF düzeylerinde yaklaşık \%34'lük artış saptanmıştır (53).

Bisiklet egzersizlerinden farklı olarak Coelho ve ark. 48 kișilik kırılgan/kırılgan olmayan yașlı kadın katılımcının olduğu çalışmada; 10 haftalık süreçte haftada üç gün $60 \mathrm{dk} \mathrm{dk}^{\prime} \mathrm{lk}$ direnç egzersizleri (1-2 hf: $1 \mathrm{MT} \% 50,2-10 \mathrm{hf}: 1 \mathrm{MT}$ $\% 75$, sekiz set sekiz tekrar) uygulamıştır. Her iki gruptaki kadın katılımclarda da egzersiz girişimleri sonucunda BDNF düzeylerinde artış saptanmıştır (54).

Pereira ve ark. 10 hafta boyunca haftada üç gün ortalama 60 dk'llk seanslardan oluşan standardize edilmiş iki egzersiz programının (kas kuvveti ve aerobik) depresif semptomlu yaşlı kadınlardaki BDNF düzeylerine etkisini incelemişlerdir. Kontrol grubu (kas kuvveti egzersizi) ilk iki hafta boyunca 1MT'nin $\% 50$ 'sinde daha sonra \%75'inde, uygulama grubu (aerobik egzersiz) ise KAHmax'ın \%6580'i arasinda bir egzersiz programı uygulamışlardır. Kuvvet egzersizi $(10$ dk'llk yürüyüş sonrası rectus femoris, psoas, hamstrings ve triceps surae kaslarma germe ardından kalça fleksiyonu, abdüksiyonu, addüksiyonu ve ekstansiyonu, diz fleksiyonu ve ekstansiyonu, mini squat) yapan kontrol grubunun BDNF düzeyleri önemli ölçüde artarken, aerobik egzersiz uygulanan gruptaki artış istatistiksel olarak anlamlı bulunmamıştır. Fakat her iki fiziksel egzersiz çeşidinin de depresif semptomlar üzerinde olumlu etki yarattığı saptanmıştır (55).

Hasta yaşlılarda yapılan bu çalışmaların sonuçlarından farklı olarak; Baker ve ark., hafif bilişsel bozukluğu olan 29 yaşlı kişi üzerinde altı ay süreyle uygulanan aerobik egzersizin, biliş ve Alzheimer ile ilişkili insülin, IGF-1, kortizol ve BDNF gibi biobelirteçlerle olan ilişkisini incelemişlerdir. Katılımcılardan aerobik egzersiz

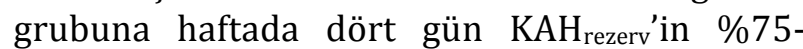
85 'inde, stretching grubuna ise $\mathrm{KAH}_{\text {rezerv' }}$ 'in $\% 50$ 'sinde ortalama 45-60 dk boyunca egzersiz yaptırılmıştır. Çalışma sonucunda gruplar arasında BDNF düzeyinde değişiklik saptanmamıştır (56). Benzer şekilde Baker ve ark. diğer çalışmalarında kullandıkları egzersiz protokolünü bu kez glükoz intoleranslı yaşlılara uygulamışlardır. Çalışma sonucunda katılımcıların BDNF düzeylerinde artış saptanmamıştır. Fakat altı ay süren aerobik egzersizler katılımclların seçici ve bölünmüş dikkat, bilișsel esneklik ve bellek gibi yürütücü işlev performanslarını olumlu yönde etkilemiştir (57).

Hvid ve ark. hareket becerileri sınırlı 47 yaşlı katılımcı üzerinde yaptıkları çalışmada; 12 hafta süreyle haftada iki gün yüksek şiddetli aralıklı güç egzersizlerinin [1-7 hf: 1(MT)\%70, üç set-10 tekrar, 7-12 hf: 1(MT)\%80, üç set-sekiz tekrar] BDNF düzeylerine etkilerini incelemişlerdir. Güç egzersizleri sonucunda yaşlıların BDNF düzeylerinde değişiklik saptanmamıştır (58). Sağlıklı ile hasta yaşlı katılımcıların fiziksel egzersize BDNF yanıtları açısından karşılaştırıldığı çalışmalar incelendiğinde; Marusiak ve ark. 22 yaşlı (11 Parkinson, 11 sağlıklı) kişi üzerinde sekiz hafta süreyle sabit bisiklet ergometresi uygulayarak egzersizin BDNF düzeyleri üzerine etkilerini incelemişlerdir. Katılımcılara haftada üç gün 40 $(5 \times 8) \quad \mathrm{dk} \quad\left(3 \mathrm{dk} \quad 260 \mathrm{rpm}, \mathrm{KAH}_{\max } \% 68+2\right.$ $\mathrm{dk} \leq 60 \mathrm{rpm}, \mathrm{KAH}_{\max } \% 62$ ) egzersiz yaptırılmıștır. 
Çalışma sonucunda; Parkinson hastalarında egzersizle sağlanan BDNF artışının nöroplastisiteye neden olduğu düşünülmüștür (59).

Allard ve ark., 24 kişiden oluşan hafif bilișsel bozukluğu olan yaşlılara altı ay boyunca haftada üç gün ortalama 45-60 dk uygulanan aerobik yürüyüş egzersizinin (\%50-70 $\mathrm{VO}_{2}$ max) $\mathrm{BDNF}$ düzeylerine etkilerini incelemişlerdir. Sonuçlar potansiyel olarak, Alzheimer hastalığının klinik öncesi aşamalarında hastalığın ilerleyişini izlemek için diagnostik bir ölçüm olarak, egzersize serum BDNF yanitının kullanılabileceğine işaret etmektedir (60). Nascimento ve ark. $67 \quad$ (37 hafif bilișsel bozukluk, 30 sağlıklı) yaşlı bireyin katılımcı olduğu çalışmada; 16 hafta boyunca haftada üç gün ortalama $60 \mathrm{dk} \mathrm{KAH}_{\max }$ 'In \%60-80'inde çoklu egzersiz modeli (kassal dayanıklılık, aerobik, motor koordinasyon, denge) uygulamıştır. Uygulama sonucunda hem hasta hem de sağlıklı egzersiz grubunun BDNF düzeylerinde önemli artış saptanmıştır (61).

\section{SONUÇ}

Çalışmanın amacına paralel nitelikteki derleme çalışmaları incelendiğinde; Szuhany ve ark. (62)'in meta-analiz çalışmasında; fiziksel egzersizin insanlarda BDNF aktivitesini arttırmak için önemli bir strateji olabileceği, bu etkilerin büyüklüğünün kadınlarda erkeklere göre daha düşük olabileceği belirtilmiştir. Cinsiyet etkisi ile oluşabilecek bu farklılığın çalışmalardaki örneklem yetersizliğinden kaynaklanabileceği, fakat gelecek çalışmalarda bu değişkenin üzerinde durulması gerektiği ortaya konulmuştur (62). Piepmeier ve Etnier ise akut egzersizin bellek üzerine etkisinde BDNF'nin etkisinin bulunabileceğini fakat literatürde farklı sonuçları ortaya koyan çalışmaların da olduğunu belirtmişlerdir (29). Coelho ve ark.nın derleme çalışmasında; yaşlıların BDNF düzeylerinde artış sağlamak için gereken fiziksel egzersizin tipi ve yoğunluğu için bir öneri protokolü olușturmanın henüz mümkün olmadığı, fakat özellikle orta şiddetteki fiziksel egzersizlerin, yaşlılarda BDNF'nin periferik düzeylerini arttırmak için daha etkili olduğu bildirilmiştir (14). Enette ve ark.; fiziksel egzersiz çeşidinin tek başına BDNF düzeyleri açısından temel faktör oluşturmadığını, egzersizin yoğunluğu ve sıklığının da önemli olduğunu ortaya koymuşlardır (63).

$\mathrm{Bu}$ derlemede literatürü destekler nitelikte sonuçların yer aldığı gözlenmiştir. $\mathrm{Bu}$ çalışmadan elde edilen verilere göre; fiziksel egzersizin BDNF düzeylerini olumlu yönde etkilediğini gösteren kuvvetli kanıtlar vardır, ancak yaşlılar üzerindeki egzersizin etkisi ile ilgili az sayıda çalıșma yapılmıştır. Yaşlılarda aerobik tarzda orta şiddetli (yürüyüş, hafif tempoda koşu, eliptik, bisiklet) egzersizlerin BDNF düzeylerine olumlu etki açısından daha uygun olduğu fakat aerobik egzersizlerin direnç egzersizleri ile birleştirildiği kombine tarzda egzersizlerin de bu olumlu etkiyi sağlayabileceği düşünülmektedir. Bilişsel stimülasyon ve hareketi birleştirebilen egzersiz modellerinin de (exergame, koordinasyon, dans) fiziksel egzersizin BDNF üzerindeki olumlu etkisini daha da arttırabilecek potansiyeldedir. Egzersizlerin uygulanma sıklığı ve süresi açısından düzenli şekilde haftada en az üç gün ortalama 30-60 dk'lık seansların yaşlılardaki BDNF düzeylerine optimal bir etki yapabileceği görülmektedir.

$\mathrm{Bu}$ popülasyonda BDNF'nin periferik düzeylerini arttırmak için fiziksel egzersiz program önerilerinde (yoğunluk, egzersiz tipi, sıklık, süre) önemli bir eksiklik olduğu görülmektedir. Özellikle cinsiyet etkilerinin dikkate alınmadığı, az katılımcının yer aldığı çalışmalardan elde edilen çelişkili sonuçların BDNF gibi biyobelirteçlerin yorumlanmasını güçleştirdiği düşünülmektedir. Ayrıca yaşlı katılımcıların hastalık çeşitlerinin, fiziksel aktivite düzeylerinin, yaş ortalamalarının ve antrenman yaşlarının BDNF düzeylerini etkileyebileceği görülmektedir. Bilişsel stimülasyon ve fiziksel egzersizi birleştirebilen yöntemlerin BDNF üzerindeki etkilerinin inceleneceği, bunun yanı sıra bazı genetik faktörlerin egzersiz-BDNF etkileşimine yönelik uzun süreli deneysel çalışmalara yer verilmelidir. Egzersizin planlanması ve uygulanması sürecinde spor bilimi uzmanlarının 
katkısının egzersizlerin amaca uygun yürütülmesi ve yaralanma riski açısından önemli olduğu düşünülmektedir.

Sonuç olarak; egzersiz, BDNF'ye etkisi aracılığı ile nöral dokunun iyileşmesi ve yenilenmesine yol açabilirse, nöromüsküler bozukluklarla ve sedanter yaşam tarzıyla ilişkili bilişsel hastalıklarla mücadelede çok güçlü bir reçete haline gelebilir.

\section{KAYNAKLAR}

1. Harada $\mathrm{CN}$, Natelson Love $\mathrm{CN}$, Triebel KL. Normal cognitive aging. Clin Geriatr Med. 2013;29(4):737-52.

2. Colcombe S, Kramer AF. Fitness effects on the cognitive function of older adults: a meta-analytic study. Psychol Sci. 2003;14(2):125-30.

3. Mock JT, Chaudhari K, Sidhu A, et al. The influence of vitamins $\mathrm{E}$ and $\mathrm{C}$ and exercise on brain aging. Exp Gerontol. 2017;94:69-72.

4. Seidler RD, Bernard JA, Burutolu TB, et al. Motor control and aging: links to age-related brain structural, functional, and biochemical effects. Neurosci Biobehav Rev. 2010;34(5):721-33.

5. Lord SR, Smith ST, Menant JC. Vision and falls in older people: risk factors and intervention strategies. Clin Geriatr Med. 2010;26(4):569-81.

6. Watson NL, Rosano C, Boudreau RM, et al. Executive function, memory, and gait speed decline in wellfunctioning older adults. J Gerontol A Biol Sci Med Sci. 2010;65(10):1093-100.

7. Powell KE, Blair SN. The public health burdens of sedentary living habits: theoretical but realistic estimates. Med Sci Sports Exerc. 1994;26(7):851-6.

8. Deslandes A, Moraes H, Ferreira C, et al. Exercise and mental health: many reasons to move. Neuropsychobiology. 2009;59(4):191-8.

9. Lista I, Sorrentino G. Biological mechanisms of physical activity in preventing cognitive decline. Cell Mol Neurobiol. 2010;30(4):493-03.

10. Cetinkaya C, Sisman AR, Kiray M, et al. Positive effects of aerobic exercise on learning and memory functioning, which correlate with hippocampal IGF-1 increase in adolescent rats. Neurosci Lett. 2013;549:177-81.

11. Diederich K, Bastl A, Wersching H, et al. Effects of different exercise strategies and intensities on memory performance and neurogenesis. Front Behav Neurosci. 2017;11:47.

12. Duzel E, van Praag H, Sendtner M. Can physical exercise in old age improve memory and hippocampal function? Brain. 2016;139(3):662-73.

13. Hillman $\mathrm{CH}$, Erickson KI, Kramer AF. Be smart, exercise your heart: exercise effects on brain and cognition. Nat Rev Neurosci. 2008;9(1):58-65.

14. Coelho FG, Gobbi S, Andreatto CA, et al. Physical exercise modulates peripheral levels of brain-derived neurotrophic factor (BDNF):a systematic review of experimental studies in the elderly. Arch Gerontol Geriatr. 2013;56(1):10-5.

15. Eggermont L, Swaab D, Luiten P, et al. Exercise, cognition and Alzheimer's disease:more is not necessarily better. Neurosci Biobehav Rev. 2006;30(4):56275 .

16. Winter B, Breitenstein C, Mooren FC, et al. High impact running improves learning. Neurobiol Learn Mem. 2007;87(4):597-609.

17. Ngandu T, Lehtisalo J, Solomon A, et al. A 2 year multidomain intervention of diet, exercise, cognitive training and vascular risk monitoring versus control to prevent cognitive decline in at-risk elderly people (FINGER): a randomised controlled trial. Lancet. 2015;385(9984):2255-63.

18. Wirth M, Haase CM, Villeneuve S, et al. Neuroprotective pathways: lifestyle activity, brain pathology and cognition in cognitively normal older adults. Neurobiol. Aging. 2014;35(8):1873-82.

19. Vemuri P, Lesnick TG, Przybelski SA, et al. Effect of lifestyle activities on Alzheimer disease biomarkers and cognition. Ann Neurol. 2012;72(5):730-8.

20. Nyberg J, Åberg MA, Schiöler L, et al. Cardiovascular and cognitive fitness at age 18 and risk of early-onset dementia. Brain. 2014;137(5):1514-23.

21. Rovio S, Kåreholt I, Helkala EL, et al. Leisure-time physical activity at midlife and the risk of dementia and Alzheimer's disease. Lancet Neurol. 2005;4(11):705-11.

22. Themanson JR, Pontifex MB, Hillman CH. Fitness and action monitoring: evidence for improved cognitive flexibility in young adults. $J$ Neurosci. 2008;157(2):319-28.

23. Alkadhi KA. Exercise as a positive modulator of brain function. Mol Neurobiol. 2018;55(4):3112-30.

24. Ahlskog JE, Geda YE, Graff-Radford NR, et al. Physical exercise as a preventive or disease-modifying treatment of dementia and brain aging. Mayo Clin Proc. 2011;86(9):876-84.

25. Voss MW, Nagamatsu LS, Liu-Ambrose T, et al. Exercise, brain, and cognition across the life span. J Appl Physiol (1985). 2011;111(5):1505-13.

26. Tolppanen AM, Solomon A, Kulmala J, et al. Leisuretime physical activity from mid-to late life, body mass index, and risk of dementia. Alzheimers Dement. 2015;11(4):434-43.

27. Mattson MP, Maudsley S, Martin B. BDNF and 5-HT: a dynamic duo in age-related neuronal plasticity and neurodegenerative disorders. Trends Neurosci. 2004;27(10): 589-94.

28. Neeper SA, Gómez-Pinilla F, Choi J, et al. Exercise and brain neurotrophins. Nature. 1995;373(6510):109.

29. Piepmeier AT, Etnier JL. Brain-derived neurotrophic factor (BDNF) as a potential mechanism of the effects of acute exercise on cognitive performance. J Sport Health Sci. 2015;4(1):14-23. 
30. Webster MJ, Herman MM, Kleinman JE. et al. BDNF and trkB mRNA expression in the hippocampus and temporal cortex during the human lifespan. Gene Expr Patterns. 2006;6(8):941-51.

31. Foster PP, Rosenblatt, KP, Kuljiš RO. Exerciseinduced cognitive plasticity, implications for mild cognitive impairment and Alzheimer's disease. Front Neurol. 2011;2:28.

32. Erickson KI, Voss, MW, Prakash RS, et al. Exercise training increases size of hippocampus and improves memory. Proc Natl Acad Sci USA. 2011;108(7):301722.

33. Kowiański P, Lietzau G, Czuba E, et al. BDNF: A key factor with multipotent impact on brain signaling and synaptic plasticity. Cell Mol Neurobiol. 2018;38(3):579-93.

34. Lynch MA. Long-term potentiation and memory. Physiol Rev. 2004;84(1):87-136

35. Leal G, Afonso PM, Salazar IL, et al. Regulation of hippocampal synaptic plastcity by BDNF. Brain Res. 2015;1621:82-101.

36. Zuccato C, Cattaneo E. Brain-derived neurotrophic factor in neurodegenerative diseases. Nat Rev Neurol. 2009;5(6):311-22.

37. Diniz BS, Teixeira AL. Brain-derived neurotrophic factor and Alzheimer's disease: physiopathology and beyond. Neuromolecular Med. 2011;13(4):217-22.

38. Lee JM, Shiroma EJ, Lobelo F, et al. Effect of physical inactivity on majör non-communicable diseases worldwide: an analysis of burden of disease and life expectancy. Lancet. 2012;380(9838):219-29.

39. Kimura K, Yasunaga A, Wang LQ. Correlation between moderate daily physical activity and neurocognitive variability in healthy elderly people. Arch Gerentol Geriatr. 2013;56(1):109-17.

40. Tsai CL, Wang CH, Pan CY, et al. The effect of longterm resistance exercise on the relationship between neurocognitive performance and GH, IGF-1, and homocysteine levels in the elderly. Front Behav Neurosci. 2015;9:23.

41. Liberati A, Altman DG, Tetzlaff J, et al. The PRISMA statement for reporting systematic reviews and meta-analyses of studies that evaluate health care interventions: explanation and elaboration. PLoS Med. 2009;6(7):e1000100.

42. Voss MW, Erickson KI, Prakash RS, et al. Neurobiological markers of exercise-related brain plasticity in older adults. Brain Behav Immun. 2013;28:90-9.

43. Leckie RL, Oberlin LE, Voss MW, et al. BDNF mediates improvements in executive function following a 1year exercise intervention. Front Hum Neurosci. 2014;8: 985.

44. Schega L, Peter B, Brigadski T, et al. Effect of intermittent normobaric hypoxia on aerobic capacity and cognitive function in older people. J Sci Med Sport. 2016;19(11):941-5.

45. Anderson-Hanley C, Arciero PJ, Brickman AM, et al. Exergaming and older adult cognition: a cluster ran- domized clinical trial. Am J Prev. Med. 2012;42(2):109-19.

46. Rehfeld K, Lüders A, Hökelmann A, et al. Dance training is superior to repetitive physical exercise in inducing brain plasticity in the elderly. PloS one. 2018;13(7):e0196636.

47. Vaughan S, Wallis M, Polit D, et al. The effects of multimodal exercise on cognitive and physical functioning and brain-derived neurotrophic factor in older women: a randomised controlled trial. Age Ageing. 2014;43(5):623-9.

48. Walsh JJ, Scribbans TD, Bentley RF, et al. Neurotrophic growth factor responses to lower body resistance training in older adults. Appl Physiol Nutr Metab. 2015;41(3):315-23.

49. Forti LN, Van Roie E, Njemini R, et al. Dose-and gender-specific effects of resistance training on circulating levels of brain derived neurotrophic factor (BDNF) in community-dwelling older adults. Exp Gerontol. 2015;70:144-9.

50. Maass A, Düzel S, Brigadski T, et al. Relationships of peripheral IGF-1, VEGF and BDNF levels to exerciserelated changes in memory, hippocampal perfusion and volumes in older adults. Neuroimage. 2016;131:142-54.

51. Matura S, Fleckenstein J, Deichmann R, et al. Effects of aerobic exercise on brain metabolism and grey matter volume in older adults: results of the randomised controlled SMART trial. Transl Psychiatry. 2017;7(7):1-9; e1172.

52. Brinkmann C, Schäfer L, Masoud M, et al. Effects of cycling and exergaming on neurotrophic factors in elderly type 2 diabetic men -A preliminary investigation. Exp Clin Endocrinol Diabetes. 2017;125(7):43640.

53. Zoladz JA, Majerczak J, Zeligowska E, et al. Moderateintensity interval training increases serum brainderived neurotrophic factor level and decreases inflammation in Parkinson's disease patients. J Physiol Pharmacol. 2014;65(3): 441-8.

54. Coelho FM, Pereira DS, Lustosa LP, et al. Physical therapy intervention (PTI) increases plasma brainderived neurotrophic factor (BDNF) levels in nonfrail and pre-frail elderly women. Arch Gerontol Geriatr. 2012;54(3):415-20.

55. Pereira DS, de Queiroz, BZ, Miranda AS, et al. Effects of physical exercise on plasma levels of brain-derived neurotrophic factor and depressive symptoms in elderly women -a randomized clinical trial. Arch Phys Med Rehabil. 2013;94(8):1443-50.

56. Baker LD, Frank LL, Foster-Schubert K, et al. Effects of aerobic exercise on mild cognitive impairment: a controlled trial. Arch Neurol. 2010;67(1):71-9.

57. Baker LD, Frank LL, Foster-Schubert K, et al. Aerobic exercise improves cognition for older adults with glucose intolerance, a risk factor for Alzheimer's disease. J Alzheimers Dis. 2010;22(2):569-79. 
58. Hvid LG, Nielsen MKF, Simonsen C, et al. Brainderived neurotrophic factor (BDNF) serum basal levels is not affected by power training in mobilitylimited older adults -A randomized controlled trial. Exp Gerontol. 2017;93:29-35.

59. Marusiak J, Żeligowska E, Mencel J, et al. Interval training-induced alleviation of rigidity and hypertonia in patients with Parkinson's disease is accompanied by increased basal serum brain-derived neurotrophic factor. J Rehabil Med. 2015;47(4):372-5.

60. Allard JS, Ntekim O, Johnson SP, et al. APOE\&4 impacts up-regulation of brain-derived neurotrophic factor after a six-month stretch and aerobic exercise intervention in mild cognitively impaired elderly African Americans: A pilot study. Exp Gerontol. 2017;87(PtA):129-36.
61. Nascimento CM, Pereira JR, de Andrade LP, et al. Physical exercise in MCI elderly promotes reduction of pro-inflammatory cytokines and improvements on cognition and BDNF peripheral levels. Curr Alzheimer Res. 2014;11(8):799-805.

62. Szuhany KL, Bugatti M, Otto MW. A meta-analytic review of the effects of exercise on brain-derived neurotrophic factor. J Psychiatr Res. 2015;60:56-64.

63. Enette L, Vogel T, Fanon JL, et al. Effect of interval and continuous aerobic training on basal serum and plasma brain-derived neurotrophic factor values in seniors: a systematic review of intervention studies. Rejuvenation Res. 2017;20(6):473-83. 